Int. J. Electrochem. Sci., 12 (2017) 1625 - 1641

International Journal of

ELECTROCHEMICAL

SCIENCE

www.electrochemsci.org

\title{
Effect of Titania Nanoparticles Loading in Sol-Gel Films for Corrosion Protection of Aluminum AA2024-T3 Alloy in 3.5\% Sodium Chloride Solution
}

\author{
Nada F. Atta, Mohamed A. Abd El Fatah, Ahmed Galal* \\ Department of Chemistry, Faculty of Science, Cairo University, 12013 Giza - Egypt \\ *E-mail: galal@sci.cu.edu.eg
}

doi: $10.20964 / 2017.02 .40$

Received: 22 October 2016 / Accepted: 14 December 2016 / Published: 30 December 2016

Sol-Gel films modified with tiania $\left(\mathrm{TiO}_{2}\right)$ was prepared and employed as a corrosion protective coating for aluminum Al2024 (UNS A92024) alloy in 3.5\% sodium chloride solution. The morphology of the coatings was analyzed using field-emission scanning electron microscope (FESEM). The protective nature of the coating was evaluated using electrochemical polarization and impedance spectroscopy measurements. The results indicated that the modification of the sol-gel coating with $\mathrm{TiO}_{2}$ increased the corrosion resistance of the alloy. The insulating and non-permeable nature of the coating resulted in a slower rate of electrolyte penetration to the underlining of the coating. On the other hand, the presence of $\mathrm{TiO}_{2}$ allowed the modification of the sol-gel structure that ended with a high cross-linked structure. However, we found that increasing the Ti-content allowed high chance for galvanic corrosion that resulted in increasing the corrosion rate. The electrochemical impedance spectroscopy measurements provided an explanation for the increased corrosion resistance of the sol-gel coating containing $\mathrm{TiO}_{2}$. The surface morphology revealed changes imparted to the surface with and without coating before and after its exposure to the corroding medium.

Keywords: Al2024-T3; Sol-gel; Titania nanoparticles; Corrosion protection; 3.5\% NaCl.

\section{$\underline{\text { FULL TEXT }}$}

(C) 2017 The Authors. Published by ESG (www.electrochemsci.org). This article is an open access article distributed under the terms and conditions of the Creative Commons Attribution license (http://creativecommons.org/licenses/by/4.0/). 